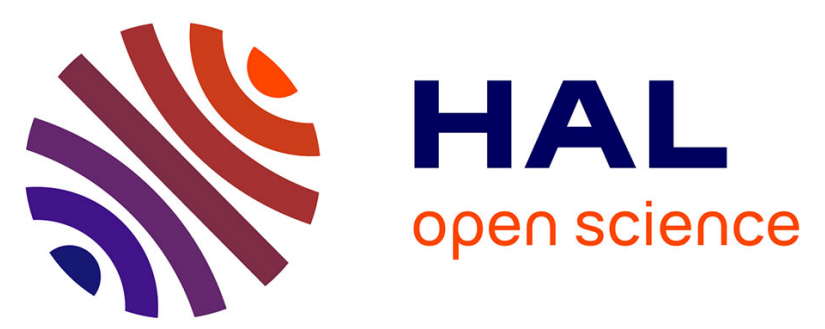

\title{
Discrete Event Simulation as a Support in the Decision Making to Improve Product and Process in the Automotive Industry - A Fuel Pump Component Case Study
}

Luis E. Villagomez, Daniel Cortés, José Ramírez, Alejandro Álvarez, Rafael Batres, Ivann Reyes, Germán Esparza, Nancy Cruz, Arturo Molina

\section{To cite this version:}

Luis E. Villagomez, Daniel Cortés, José Ramírez, Alejandro Álvarez, Rafael Batres, et al.. Discrete Event Simulation as a Support in the Decision Making to Improve Product and Process in the Automotive Industry - A Fuel Pump Component Case Study. 20th Working Conference on Virtual Enterprises (PRO-VE), Sep 2019, Turin, Italy. pp.572-581, 10.1007/978-3-030-28464-0_50 . hal-02478787

\author{
HAL Id: hal-02478787 \\ https://hal.inria.fr/hal-02478787
}

Submitted on 14 Feb 2020

HAL is a multi-disciplinary open access archive for the deposit and dissemination of scientific research documents, whether they are published or not. The documents may come from teaching and research institutions in France or abroad, or from public or private research centers.
L'archive ouverte pluridisciplinaire HAL, est destinée au dépôt et à la diffusion de documents scientifiques de niveau recherche, publiés ou non, émanant des établissements d'enseignement et de recherche français ou étrangers, des laboratoires publics ou privés. 


\title{
Discrete Event Simulation as a Support in the Decision Making to Improve Product and Process in the Automotive Industry - A Fuel Pump Component Case Study
}

\author{
Luis E. Villagomez ${ }^{1}$, Daniel Cortés ${ }^{1}$, José Ramírez ${ }^{1}$, Alejandro Álvarez ${ }^{1}$, Rafael \\ Batres $^{1}$, Ivann Reyes ${ }^{2}$, Germán Esparza ${ }^{3}$, Nancy Cruz ${ }^{3}$ and Arturo Molina ${ }^{1}$ \\ ${ }^{1}$ Tecnologico de Monterrey, School of Engineering and Sciences, 14380, Mexico City, \\ Mexico \\ \{levg, a01655708, a00995924, a01421567, rafael.batres, armolina\}@tec.mx \\ ${ }^{2}$ Grupo Dinamex, S.A. Technical Support, Mexico, 52976, Lopez Mateos, Mexico \\ \{ireyes\}@dinamex.com.mx \\ ${ }^{3}$ SIEMENS PLM Mesoamerica,, Mexico city, Mexico \{german.esparza, \\ nancy.cruz\}@siemens.com
}

\begin{abstract}
In Mexico, the automotive sector is one of the most profitable industrial activities as it contributes $2.9 \%$ of the national GDP [1]. However, there still exist facilities that are in transit of manufacturing processes improvement. In recent years, the adoption of emergent technologies, practices and tools that lead into the Industry 4.0, has been a parameter to compete and remain competitive in the global market. Upgrading all the processes is not always a viable solution. Thus, companies must identify the optimal solution to increase their productivity. Numerous technologies are available to facilitate this migration. This paper aims to show how discrete event simulation with an action research cycle supports the decision making in process improvement aided by the information collected in Collaborative Networks. A case study is shown in the automotive sector to validate changes in processes based on estimated energy consumption, maintenance strategies, process time reduction and the implementation of state-of-the-art sustainable processes.
\end{abstract}

Keywords: Automotive Industry; Discrete Event Simulation; Plant Simulation; Plasma Nitriding; Modeling and simulation; Collaborative Networks.

\section{Introduction}

In recent years, Industry 4.0 has been a parameter of progress among the developing countries [2][3][4]. The adoption of new information technologies and techniques can promote sustainable motives [5] within a circular economy [6], with an integral society [7] and environmental benefits [8][9]. According to Stock \& Seliger (2016) [10], sustainability trends are based on macro perspectives, such as value creation networks and business models but also on a micro perspective such as improvements in product, process, manufacturing equipment, organization optimization and better management of human resources, through end-to-end engineering, vertical and 
horizontal integration. This interconnectivity allows for the creation of smart factories that implement the emergent technologies, practices and tools to create environments where hardware and software interact in real-time and enable manufacturing information flow. Interconnection, information transparency and decentralised decisions are the principles that promote manufacturing firms into Industry 4.0 [11]. In fact, the natural way to migrate from a traditional manufacturing firm into sensing, smart and sustainable firm system. This can be achieved by implementing Collaborative Networks $(\mathrm{CN})$, which in turn enable those principles as a native evolution. $\mathrm{CN}$ not only allows the relationship among different areas of the manufacturing firm but also delivers information flow about the individual processes along all the productive line giving information that can be used to perform improvements. In this way, process optimisation can be monitored and reduced using adequated technology that can be rapidly assessed using $\mathrm{CN}$. A commonly resource subject to optimisation among industries is energy consumption. For this, Otis et al. (2017) [12] establishes a relationship on the reduction of energy consumption with the improvement of manufacturing process plans, such as reduction of start-up times, execution of preventive maintenance, proper planning of the master production program and materials.

Within a manufacturing complex, there exist many entities where either big or small adjustments could be carried out to improve the production process [13], however, it identifies the changes that result in better economic and sustainable outcomes. Decision-making practices driven by $\mathrm{CN}$ and based on knowledge to improve the quality of processes and the use of technological tools like Tecnomatix Plant Simulation software allow to visualise and evaluate in detail the effects of such decisions on the plant layout to find the optimal results. This paper focuses on a simulation-based and $\mathrm{CN}$ approach applied to a production system to assess the advantages of migrating to sustainable technology. This system is owned by a Mexican company, which is dedicated to aftermarket spare parts. A CN was used to link information related to manufacturing into the decision-making process and pursue the motives of a manufacturing firm in the automotive sector. In Section 2, presents a brief introduction of how Discrete Event Simulation (DES) can be used to model complex production systems. Then, in Section 3, Action Research is described. Subsequently, in Section 4, the authors explain the use of DES to the creation of a collaborative network. Furthermore, in Section 5, discusses the results obtained with a case study. Finally, in Section 6 presents the conclusions and future work.

\section{Discrete Event Simulation}

Computer simulation is described as an attempt to model a real or hypothetical situation. Computational simulation is divided into continuous simulation and discrete event simulation (DES). DES tracks the changes in the components of a model when they occur. Unlike a continuous simulation, where the clock runs constantly, DES clock jumps from one event to the next, showing only the state changes of the model components at certain moments. Negahban and Smith (2014) [14] showed that DES is an effective tool to assist the plant design and operation but recognised that there is still the need of supporting with more efficient techniques to deal with the complexity 
of manufacturing systems. DES has been adopted as an instrument from Industry 4.0 $[15][16][17]$ to analyse and optimise decisions ranging from production decisions to supply chain management. It provides the ability to visualise changes in specific variables, relevant aspects for the stakeholders, supply chain, human safety. In general, scenarios that would prevent costs for the decision makers [18][19]. Thus, enterprises have been benefited with the introduction of simulation, achieving results in an agile manner. For instance, manufacture in the automotive sector is based on the sequence of operations, known as discrete events [20] which assemble parts from different suppliers into a complete product. For this automotive production, plants could be studied as a discrete event phenomenon that can be easily modelled in DES software.

\section{Action Research Cycle}

Chavarría-Barrientos et al. (2018)[21] proposed a model typology. The model typology is composed of three types of models, namely, black-box model, operation model and integrated operation model, which vary in terms of the level of complexity that is required by the simulation task. A "Black box" (Fig. 1a) represents the main activity of the process which simplifies details about the behaviour of the process components [22]. A black box model is useful for a preliminary estimation of the productive capacity of the integrated activities involving the process. Scenarios with this level of detail can be found in [23][24]. Aspects such as layout configuration, operator actions, material transport, and operating strategies are not considered.

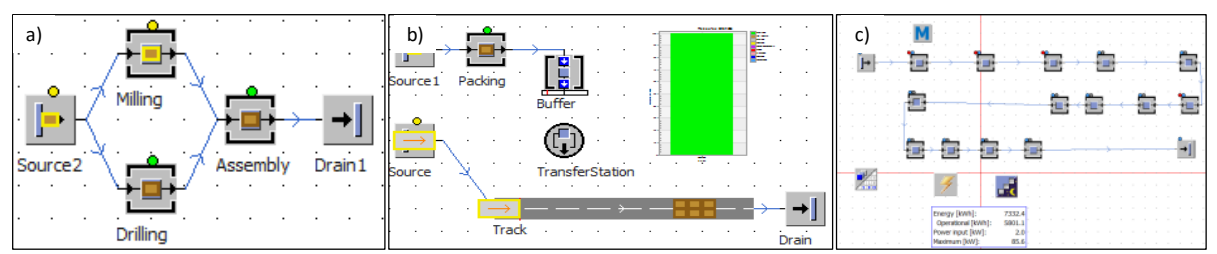

Fig. 1. Model typology from left to right, a) Black box model, b) operation model and c) integrated operating model.

An Operation Model (Fig. 1b) is a building block for creating an integrated model of operations. This level of detail is suitable for modelling a specific activity, a workstation or a small process [25]. Benefits reach from a clear understanding of the process to rapid identification of possible problems or improvements. In this case, detailed behavioural aspects of the process are considered (idle times, failures, material transport, parameters, and so on). The Integrated Operating Model (Fig 1c) is the interaction of operation models blocks and black box models working together. Because of the multiple interactions between models, numerous variables and scenarios can be tested for evaluation of worker efficiency, machine failure, processing times, buffer efficiency, among others. This type of simulation is richer in terms of information processed and enabler to make decisions, however, compared 
with the black box or operation model, it requires more interaction between all stakeholders to gather information to simulate i) the real scenario and ii) optimise multiple alternatives. Chavarría-Barrientos et al. (2018) [20] proposed a methodology, based on the Action-Research Cycle (ARC) (See Fig. 2) to develop simulation models.

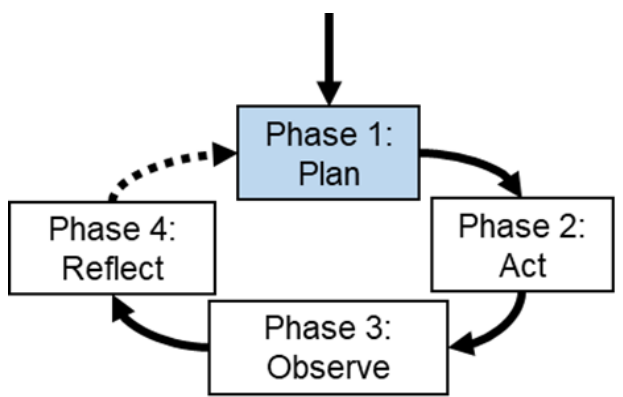

Fig. 2. Action-Research cycle.

Thus, to develop a simulation model (See Fig. 3), it is necessary to accomplish the stages described below:

- Plan: define problem, target, objectives, and how objectives might be evaluated. Planning provides information about resources available, time and relevant information for those in charge of the project.

- Act: Determine the type of model according to model typology (Fig. 1), data gathering, develop a model and validate the model. The type of model would impact directly on the information needed to be precise in the simulation model. Permits and key informants are the backbones for a useful simulation.

- Observe: Simulate the model and evaluate the objectives. The objectives proposed in the planning stage must be related to the results obtained from the simulation. Optimisation of the manufacturing process plan is expected with simulation models.

- Reflect: Identify one or more courses of action according to the results of the observing step. Restart the cycle if the objectives are not accomplished in the simulation scenarios. The results obtained from the simulation must provide valuable information for decision-makers.

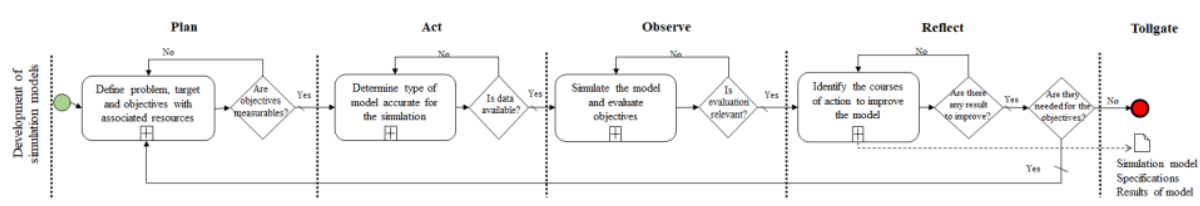

Fig. 3. Development of simulation models. Proposed technique based on ARC

\section{DES to Support the Creation of a Collaborative Network}

According to Gobbo et al. (2018) [26], industrial safety and environmental protection are linked to the concept of Industry 4.0. However, as manufacturing becomes more 
complex, factories face the challenge to minimise costs, improve processes and reduce the time of implementation deployment and revamping of production lines. These challenges are generally out of the expertise of the self-company; thus, they need to collaborate further with different actors to deal with these problems. Manufacturing firms rely on $\mathrm{CN}$ to manage the core processes of the business model, allowing the integration of different actors whose synergy help decision makers to improve and reach a common objective by providing the necessary technologies, practices and tools to solve problems in a shorter period. However, making use of the ARC to simulate different scenarios, guides them into novel practices to optimise resources and improve the productivity of the manufacturing system.

DES simulation is enriched by the information provided by multiple stakeholders. Once identified the main objective to optimise, it becomes a valuable tool as is ubiquitous and allows to make evaluations about the implementation of new technologies through the creation of virtual scenarios in a shorter period. Thus, forecasting a precise result and permitting early identification of opportunity areas by modeling and simulating different scenarios. In this way, the use of resources is reduced compared to commissioning or physical experiments [27]. DES has been widely adopted in the automotive sector, and one of the common uses is the optimisation of raw materials for the creation of parts. Solutions reached by simulation models are compared against the actual production process. DES is a tool to evaluate the ideas generated by the ARC technique with the information provided by $\mathrm{CN}$ to generate effective decision making without executing an implementation or generating additional costs by physical tests. All in all, a feasible solution is put in practice into the manufacturing firm (See Fig. 4).

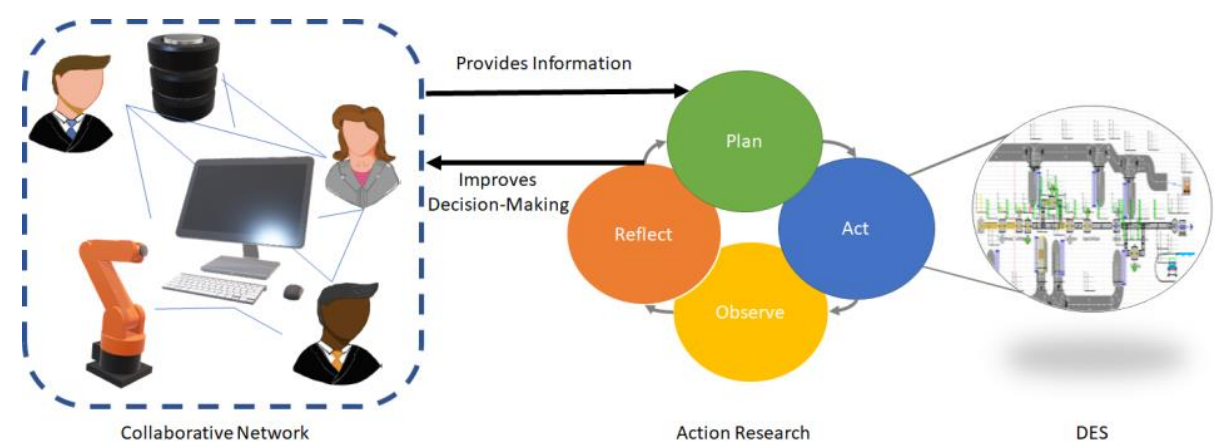

Fig. 4 A proposed framework to aid decision-making in the CN context using DES

\section{Case Study}

A case study is developed in Grupo Dinamex S.A., a fifty-year-old company, which has a long tradition and expertise in manufacturing processes and distribution of automotive products for the aftermarket. Despite its long presence in the local market, the introduction of low-cost products from Asia motivated it to improve their processes and reduce costs. This work is focused on optimising the production of one 
of the critical components for an electric fuel pump, which is called the turbine impeller. For the creation of this component (formed by eleven metallic parts), different manufacturing processes are required such as die-cutting, boring, reaming, polishing, lapping, deburring, among others. Components exposed to wear and corrosion are also heat treated in several gas ovens. The heat treatment process was identified as a bottleneck since it cannot maintain the takt time (working time between consecutive units) of the process. This process handled salts that can be harmful to health and the environment. To reduce cost and to improve processing time, plasma nitriding heat treatment is proposed. Pilot testing was run by Termoinnova S.A de C.V, which is a company dedicated to heat treating and surface coating in different materials. The nitrided parts pass the design requirement, and they have a higher ratio between the number of parts produced over the production time than the traditional heat treatment applied in Dinamex. The use of this heat treatment has not been contemplated for the production of media components. To be able to make the collaboration, plasma nitriding application might be justified in terms of improving the process and the product. It was decided to collaborate with Tecnologico de Monterrey. In order to evaluate the plasma nitriding alternative, black box models were developed, and the process was simulated using DES.

\subsection{Process Changes and Decision Making}

Before making changes in the actual production line, a diagnosis based on the project executed by [28] allowed to know the status of the process's productivity and energy consumption in the production line. DES software (Siemens Plant Simulation) was used to experiment with different scenarios for the evaluation of the current state of the production line to make proposals for improvement in the processes. However, the result had to be evaluated and comply with the economic, personnel and technology restrictions. The simulation structure is carried out using the Action-Research cycle.

\subsection{Action Research Cycle}

Plan. The objective is to evaluate the feasibility of changing traditional heat treating with a plasma nitriding process. The feasibility is evaluated by energy consumption and processing times of a 1040 steel component.

Act. A black box model [20] is selected from the model typology to represent each of the twenty-four activities of the current process (Fig. 4a). The model was developed in Tecnomatix Plant Simulation. By using this model type, the distance between processes, the number of operators and the time of material transfer between processes were not considered. Only considers the process times, idle time and failures. The process was operated according to a schedule consists of a work shift of nine and a half hours with a break of 30 minutes and a proposed process line operating only five days a week. Process flow diagrams and the study of process times were gathered during a previous project [28]. On the other hand, energy consumption was estimated by the maintenance team of the company. Energy consumption was calculated by knowing the supply voltage, the current consumed, by the machine in different states and the power factors delivered by the manufacturer or identified on the nameplate of the machine. 
Observe. Once the model was created in Plant Simulation, a debugging of possible errors was made, and the simulation was run for an equivalent time of five days. In this way, an estimated production is calculated for a normal work week. The results of the new simulation were compared with the current production data. The simulation of the modified process shows an improvement in the number of produced parts and energy consumption. In this iteration of $\mathrm{ARC}$, the frequency of machine failures was not considered, such as electrical system failures, hydraulic or mechanical system failure as well as failures due to the breaking of cutting tools.

Reflect. With the result of the simulation, it was decided to restart the cycle, modify the model and run additional simulations. This decision was motivated by the difference between simulation and real production statistics.

\subsection{Restart the Cycle}

In the stage of planning, the objectives and objectives measures are maintained. Meanwhile, new data were collected as indicated by the methodology (Act), such as failure frequency and the time it takes the process to recover from them. It should be noted that initially, a preventive maintenance plan was missing. Only a corrective maintenance program was managed. When the fault's data was introduced into the model, the production system behaviour is like the physical production system (Observe), and data of the current processes was saved for further analysis. A new cycle (Reflect) was required to model and simulate the process improvement options such as the application of new technology and a decrease in the frequency of failures. The introduction of the new heating process results in a modified production system with fewer processes (15 instead of the 24 processes in the original production system). Plasma nitriding removes engineering restrictions to manufacture the product. This situation allows to introduce a set of new processes such as blasting process to remove the burr of the pieces coming from stamping, and the acquisition of a twin head drill to perform simultaneous drilling operations (Fig. 5).

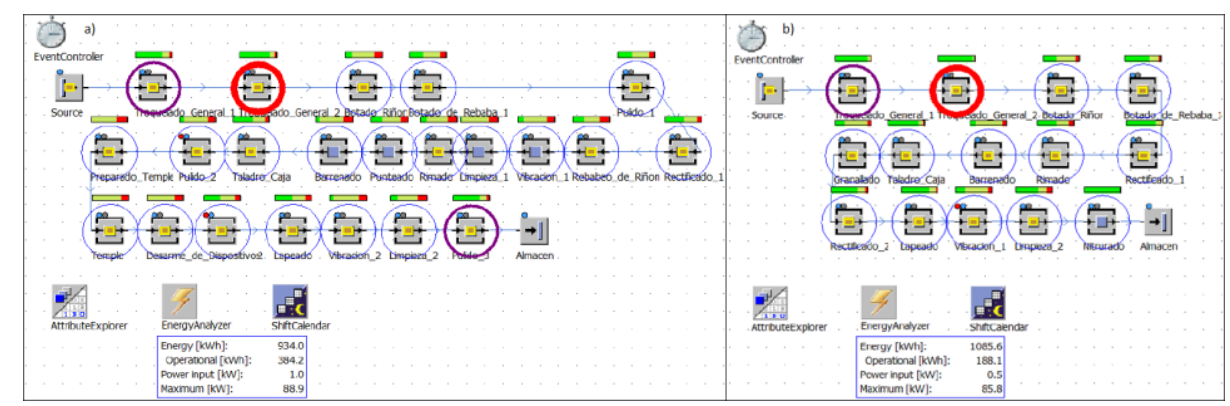

Fig. 5 A black box model of a) the current metallic turbine impeller processes, b) the proposed metallic turbine impeller processes including plasma nitriding.

Plasma nitriding allowed the product to incorporate softer materials and give a similar or longer lifetime compared to the original design material selection. With the new heat treatment process, the number of maintenance actions in the dies was 
reduced due to wear, and it is expected to see a reduction in the frequency of stoppages caused by the tooling failure. On the other hand, the application of preventive maintenance may achieve a reduction in the frequency of failures by $50 \%$.

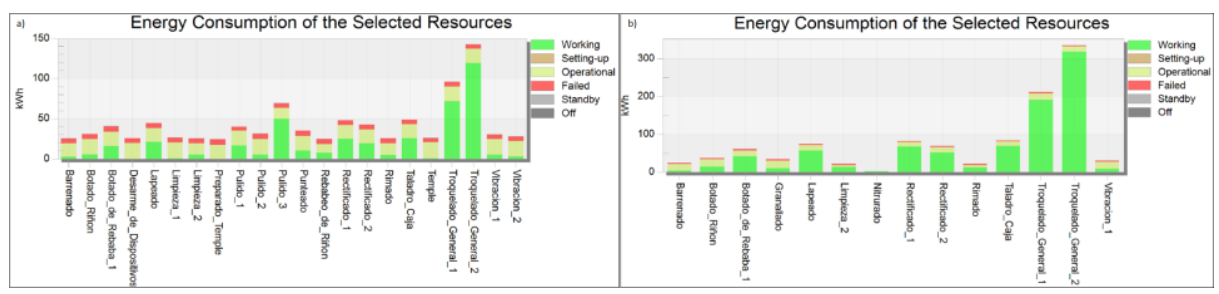

Fig. 6 Energy consumption of a) the current process for the creation of the turbine impeller, b) the proposed process for the creation of the turbine impeller.

Applying the methodology by [20], a simulation of the model with the improvements proposed was run, and as shown in Fig. 5b, the model of the production system alternatives has a considerable reduction in the number of processes. This same figure remarks that Stamping 1 and 2 consume most of the energy. However, the energy consumption of the stations when they are in failures or in idle time has a considerable reduction, as can be seen in Fig. 5b. In the simulation of the original process (Fig. 6a) has a consumption of $934 \mathrm{kWh}$, in 5 days. On the other hand, the simulation with the modified process (Fig. 6b) gives us the consumption of $1,085 \mathrm{kWh}$. According to this value, the machines are operational longer, instead of waiting. The improved process can deliver $268 \%$ more parts in the same period. An equivalent production of the current number of pieces with the modified process, energy consumption will be closed to $400 \mathrm{kWh}$, and the production line only works a day and a half instead of five days.

\section{Conclusions}

DES was used as part of the action research cycle to improve decision-making generated with the collected information of a Collaborative Network. CN for this article is comprised of a private industry, academic researchers and different systems connected through the Internet. The framework arose naturally aided by different subsystems which gather and share information. The main motivation for this work was to reduce energy consumption in a manufacturing firm, which is reflected after the implementation of the model. With these applications, considering that the remaining components of the piece belong to the same product family, an $80 \%$ reduction in gas consumption of the company is estimated; $46 \%$ savings in direct costs, close to $84 \%$ of the time of processes and a reduction of more than $50 \%$ in energy consumption. Discrete event simulation assists in creating different scenarios, where changes in processes can be properly tested while the processes are kept running daily. For future work, it is planned to create a highly complex simulation, in which a user can make production planning evaluations for multiple products that share similar processes. This new simulation should include the preparation times, the material transfers, the number of operators and a more detailed operation logic. 
DES as a Support in the Decision Making to Improve Product and Process 571

\section{Acknowledgement}

A special mention is made to the company Grupo Dinamex S.A. for allowing us to do this work, giving us the flexibility to obtain the necessary data for the creation and simulation of the model. Termoinnova S.A. de C.V. for nitriding parts and making the product test and measuring hardness in components.

In Memoriam, Engineer Antonio Salim Guraieb Kuri, CEO of Grupo Dinamex S.A.

\section{References}

1. AMIA (2018). Boletín de Prensa. Diálogos con la Industria Automotriz. Retrieved from http://www.amia.com.mx/boletin/dlg20182024.pdf

2. Hamzeh, R., Zhong, R., \& Xu, X. W. (2018). A Survey Study on Industry 4.0 for New Zealand Manufacturing. Procedia Manufacturing, 26, 49-57.

3. Santos, C., Mehrsai, A., Barros, A. C., Araújo, M., \& Ares, E. (2017). Towards Industry 4.0: an overview of European strategic roadmaps. Procedia Manufacturing, 13, 972-979.

4. Sung, T. K. (2018). Industry 4.0: A Korea perspective. Technological Forecasting and Social Change, 132, 40-45.

5. Weichhart, G., Molina, A., Chen, D., Whitman, L. E., \& Vernadat, F. (2016). Challenges and current developments for Sensing, Smart and Sustainable Enterprise Systems. Computers in Industry, 79, 34-46.

6. Saidani, M., Yannou, B., Leroy, Y., Cluzel, F., \& Kendall, A. (2019). A taxonomy of circular economy indicators. Journal of Cleaner Production, 207, 542-559.

7. Stock, T., Obenaus, M., Kunz, S., \& Kohl, H. (2018). Industry 4.0 as an enabler for a sustainable development: A qualitative assessment of its ecological and social potential. Process Safety and Environmental Protection, 118, 254-267.

8. De Sousa Jabbour, A. B. L., Jabbour, C. J. C., Foropon, C., \& Godinho Filho, M. (2018). When titans meet - Can industry 4.0 revolutionise the environmentally-sustainable manufacturing wave? The role of critical success factors. Technological Forecasting and Social Change, 132, 18-25.

9. Moktadir, M. A., Ali, S. M., Kusi-Sarpong, S., \& Shaikh, M. A. A. (2018). Assessing challenges for implementing Industry 4.0: Implications for process safety and environmental protection. Process Safety and Environmental Protection, 117, 730-741.

10. Stock, T., \& Seliger, G. (2016). Opportunities of Sustainable Manufacturing in Industry 4.0. In Procedia CIRP.

11. Hermann, M., Pentek, T., \& Otto, B. (2016, 5-8 Jan. 2016). Design Principles for Industrie 4.0 Scenarios. Paper presented at the 2016 49th Hawaii International Conference on System Sciences (HICSS).

12. Paul T. Otis, P.E., Douglas Hampson. (2017). Improve Production Scheduling to Increase Energy Efficiency. CEP Magazine. Retrieved from: https://www.aiche.org/resources/publications/cep/2017/march/improve-productionscheduling-increase-energy-efficiency

13. Singh, J., \& Singh, H. (2012). Continuous improvement approach: State-of-art review and future implications. International Journal of Lean Six Sigma.

14. Negahban, A., \& Smith, J. S. (2014). Simulation for manufacturing system design and operation: Literature review and analysis. Journal of Manufacturing Systems, 33(2), 241261. 
15. Antonelli, D., Litwin, P., \& Stadnicka, D. (2018). Multiple System Dynamics and Discrete Event Simulation for manufacturing system performance evaluation. Procedia CIRP, 78, 178-183.

16. Barrera-Diaz, C. A., Oscarsson, J., Lidberg, S., \& Sellgren, T. (2018). Discrete Event Simulation Output Data-Handling System in an Automotive Manufacturing Plant. Procedia Manufacturing, 25, 23-30.

17. Guimarães, A. M. C., Leal, J. E., \& Mendes, P. (2018). Discrete-event simulation software selection for manufacturing based on the maturity model. Computers in Industry, 103, 1427.

18. Benefits of simulation-driven development. (2016). World Pumps, 2016(2), 18-20.

19. Kurkalova, L. A., \& Carter, L. (2017). Sustainable production: Using simulation modelling to identify the benefits of green information systems. Decision Support Systems, 96, 83-91.

20. Silva, M. (2018). On the history of Discrete Event Systems. Annual Reviews in Control, 45, 213-222.

21. Chavarría-Barrientos, D., Villagomez, L. E., Miranda, J., Molina, A., Batres, R., Gutierrez, I., ... Puente, J. (2018). A Methodology to Support Manufacturing System Design Using Digital Models and Simulations: An Automotive Supplier Case Study. IFACPapersOnLine, 51(11), 1598-1603.

22. Schriber, T. J., Brunner, D. T., \& Smith, J. S. (2018). Inside discrete-event simulation software: How it works and why it matters. In Proceedings - Winter Simulation Conference.

23. Siderska, J., (2016). Application of Tecnomatix Plant Simulation for Modeling Production and Logistics Processes. Business, Management and Education, vol. 14, no. 1, pp. 64-73. ISSN 2029-7491.

24. Kliment, M., Popovic, R. and Janek, J., (2014). Analysis of the production process in the selected company and proposal a possible model optimization through PLM software module Tecnomatix Plant Simulation. Procedia Engineering, vol. 96, pp. 221-226. ISSN 18777058 .

25. Musil, M., Laskovský, V. And Fialek, P., (2016). Analysis Of Logistic Processes Using The Software Tecnomatix Plant Simulation. International Conference on Industrial Logistics. Zakopane, Poland, pp. 195-200. ISBN 9788362079063.

26. Gobbo, J. A., Busso, C. M., Gobbo, S. C. O., \& Carreão, H. (2018). Making the links among environmental protection, process safety, and industry 4.0. Process Safety and Environmental Protection, 117, 372-382.

27. Ranke, D., \& Lanza, G. (2018). Planning, Evaluation and Optimization of Product Design and Manufacturing Technology Chains for New Product and Production Technologies on the Example of Additive Manufacturing. Procedia CIRP, 70, 108-113.

28. Reyes Vega, Ivann (2016). Optimización de procesos y recursos en una línea de producción metal mecánica automotriz. Instituto Politécnico Nacional UPIICSA, Ciudad de México. 